\title{
CONTRIBUIÇÕES DA EDUCAÇÃO AMBIENTAL E HORTA ESCOLAR NA PROMOÇÃO DE MELHORIAS AO ENSINO, À SAÚDE E AO AMBIENTE
}

\section{CONTRIBUTIONS FROM ENVIRONMENTAL EDUCATION AND GARDEN SCHOOL IMPROVEMENTS IN PROMOTING THE TEACHING, THE HEALTH AND THE ENVIRONMENT}

\author{
Sandra Lucia de Souza Pinto Cribb \\ Centro Universitário Plínio Leite/Programa de Pós-Graduação Stricto Sensu, \\ sandralucribb@yahoo.com.br
}

\section{Resumo}

Este artigo apresenta a importância da educação ambiental através de atividades desenvolvidas na horta escolar. As atividades contribuem para a modificação nos hábitos e atitudes de alunos do ensino fundamental e do ensino médio quanto à percepção que eles possuem da natureza. A formação da consciência de respeito e cuidado; da necessidade da conservar o meio ambiente. A alimentação das crianças melhora, pois, passam a aceitar melhor as verduras, legumes e frutas. Os trabalhos desenvolvidos na horta criam a percepção da solidariedade, fundamental para trabalhar em grupo. Constrói o senso de responsabilidade, de valores mais humanizados e permeia todo o processo educativo estabelecendo desde cedo relações saudáveis com o meio ambiente e entre as pessoas, formando cidadãos capazes de assumir novas atitudes na busca de soluções para os problemas socioambientais. Enfim, estimula o cuidado na busca da melhoria da qualidade de vida de humanos e de outras formas de vida.

Palavras-chave: Educação Ambiental, Horta Escolar, Interdisciplinaridade, Questões socioambientais.

\begin{abstract}
This article presents the importance of the environmental education through activities in the school garden. The activities contribute to the change in habits and attitudes in elementary and high school students regarding the perception they have about the nature. The formation of the consciousness of respect and care, the need to conserve the environment. The feeding of children improves, because they begin to accept vegetables and fruits. The works developed in the garden school create a sense of solidarity, essential for working in groups. Build a sense of responsibility, values more humanized and permeates the whole educational process establishing since early health relationships with the environment and among people, educating citizens able to take on new attitudes in seeking solutions to environmental problems. Finally, it encourages the care in the pursuit of improving the quality of life of humans and other life forms.
\end{abstract}

Keywords: Environmental Education, School Vegetables, interdisciplinary, social environmental issues. 


\section{Introdução}

Cada vez está mais evidente a importância de uma educação de qualidade que leve em consideração a formação de cidadãos mais críticos, responsáveis e capacitados para a vida. Para tal realização o Ministério da Educação concebe como essencial o acesso ao conhecimento de forma ampla, bem como o acesso às novas tecnologias; além do estímulo a atividades que contribuam para conscientização sobre a importância da melhoria das condições ambientais. Também observa a necessidade de serem construídas novas visões educacionais que integrem a saúde e o ambiente através de propostas interdisciplinares.

Considerando este pensamento nos voltamos para o desenvolvimento de trabalhos realizados em horta escolar para abordar temas como educação ambiental, e educação para a saúde através dos aspectos nutricional e alimentar.

As atividades realizadas na horta escolar contribuem para os alunos compreenderem o perigo na utilização de agrotóxicos para a saúde humana e para o meio ambiente; proporciona uma compreensão da necessidade da preservação do meio ambiente escolar; desenvolve a capacidade do trabalho em equipe e da cooperação; proporciona um maior contato com a natureza, já que crianças dos centros urbanos estão cada vez mais afastadas do contato com a natureza. Proporciona também a modificação dos hábitos alimentares dos alunos, além da percepção da necessidade de reaproveitamento de materiais tais como: garrafas pet, embalagens tetra pak, copos descartáveis, entre outros. Tais atividades auxiliam no desenvolvimento da consciência de que é necessário adotarmos um estilo de vida menos impactante sobre meio ambiente bem como a integração dos alunos com a problemática ambiental vivenciada a partir do universo da horta escolar.

Numa horta escolar há possibilidade de se trabalhar diversas atividades, dentre as quais, os conceitos, princípios, o histórico da agricultura, a importância da educação ambiental, a importância das hortaliças para a saúde. Além das aulas práticas onde se trabalham as formas de plantio, o cultivo e o cuidado com as hortaliças.

$\mathrm{Na}$ formação e no início das atividades na horta escolar, todos podem e devem se envolver. Toda a comunidade escolar pode colaborar na limpeza do terreno, na formação dos canteiros e com a aquisição das sementes recomendadas pelo professore responsável pela horta, observando à característica do solo, as influências climáticas, a 
facilidade de transplantio, a resistência à "pragas", enfim, aspectos que influenciam no desenvolvimento das plantas.

A partir do número de canteiros, em sala de aula calcula-se junto com os alunos: a área de cada canteiro e a distância entre eles; a distância entre as covas para colocar as sementes de espécies de plantio definitivo, o número de covas, o número de sementes colocadas em cada cova, o tempo de germinação, o período apropriado para colheita. Tal tarefa pode ser acompanhada por um professor de matemática.

Para as espécies de transplantio, frente à inexistência ou impossibilidade de aquisição de sementeiras, podemos proceder a utilização de caixas (de isopor) de ovos vazias; posteriormente adquiri-se duas sementeiras, o que facilita a produção das mudas de hortaliças de transplantio.

Se o espaço destinado a formação da horta for provido de árvores frutíferas providencia-se a poda das mesmas (caso estejam muito altas) para possibilitar maior entrada de sol e facilitar o bom desenvolvimento dos legumes, verduras e das plantas ornamentais. Os frutos distribuídos aos alunos ou encaminhados ao restaurante do colégio e servidos como sobremesa.

Recomenda-se deixar um dos canteiros para a formação de um minhocário. Para tanto, é oportuno que se adquira uma boa quantidade de composto orgânico. Uma parte deste material pode ser utilizada também na adubação dos canteiros e de jardins, se houver.

Além da produção de hortaliças, duas outras atividades são interessantes, a saber, a realização de feirinhas para que seja vendida parte da produção, e a outra é a produção de plantas ornamentais destinadas a organizar os jardins ou jardineiras e posteriormente, se for possível, colocar as mudas à venda.

\section{Educação ambiental e a horta escolar}

A questão ambiental vem sendo amplamente debatida e ganhando cada vez mais atenção em muitos e diferentes contextos sociais, assumindo crescente importância nas instâncias política, acadêmica e na mídia.

A partir da revolução científica o homem passou a se relacionar com a natureza de forma dominadora. O modelo de desenvolvimento definido a partir da Revolução Industrial acarretou uma intensificação da destruição dos recursos naturais provocando reações e a organização de parcelas da sociedade em torno da preservação 
da natureza. A partir da década de 70 do século $\mathrm{XX}$ os debates sobre a questão ambiental aumentaram, surgiram os movimentos ambientalistas, que compreendiam a problemática ambiental como uma crise que já atingia toda a civilização frente à degradação ambiental. Após a realização de vários encontros nacionais e internacionais, envolvendo instituições governamentais e não-governamentais, foi indicado nos documentos resultantes destes eventos que uma das estratégias utilizadas para conter o processo de destruição da natureza seria a educação. Através de uma nova dimensão - a Educação Ambiental - que surge como um processo educativo que conforma um conhecimento ambiental que se traduz em valores éticos.

Cabe destacar que estamos falando da Educação Ambiental Crítica cujo objetivo é "contribuir para uma mudança de valores e atitudes, contribuindo para a formação de um sujeito ecológico" (CARVALHO, 2004, p.18 -19). Ou nas palavras de Guimarães (2004, p. 25) "capaz de contribuir com a transformação de uma realidade que historicamente se coloca em uma grave crise socioambiental”. A Educação Ambiental Crítica também denominada Emancipatória (LOUREIRO, 2009, p. 32)

"é o meio reflexivo, crítico e auto-crítico contínuo, pelo qual podemos romper com a barbárie do padrão vigente de sociedade e de civilização, em um processo que parte do contexto societário em que nos movimentamos, do "lugar" ocupado pelo sujeito, estabelecendo experiências formativas, escolares ou não, em que a reflexão problematizadora da totalidade, apoiada numa ação consciente e política, propicia a construção de sua dinâmica. (...). Emancipar não é estabelecer o caminho único para a salvação, mas sim a possibilidade de construirmos os caminhos que julgamos mais adequados à vida social e planetária, diante da compreensão que temos destes em cada cultura e forma de organização societária, produzindo patamares diferenciados de existência”.

A Educação Ambiental representa uma ferramenta fundamental para estabelecer uma ligação mais estreita entre o ser humano e a natureza. Uma transformação social de caráter urgente que busque conforme Sorrentino (2005), a superação das injustiças ambientais e sociais na humanidade.

Representa também aquilo que Boff (2008, p.11-12) manifesta acerca de uma busca de outras visões de futuro para o planeta e para a humanidade. Visões que se 
apóiem em um ethos cuja essência fundamental é o cuidado, onde haja princípios, valores e atitudes que façam da vida "um bem-viver e das ações um reto agir". Precisamos ter mais atitudes para com o a vida do planeta e com o próximo que se traduzam em cuidado. "Cuidar é mais que um ato; é uma atitude. Portanto, abrange uma atitude de ocupação, preocupação, de responsabilização e de envolvimento afetivo com o outro" (BOFF, 2008, p. 33).

Esta abordagem requer uma visão interdisciplinar, isto é, uma compreensão para além da ecologia, da biologia e da química. Gallo cita como exemplo os problemas ecológicos e menciona que estes não podem mais ser abarcados apenas pela perspectiva de uma disciplina como a biologia, ou a geografia, ou a química, ou a política etc.

"A ecologia constitui-se num novo território de saber, marcado pela interseção de vários campos de saberes, como estes já citados, além de muitos outros. Podemos chamar os problemas ecológicos de problemas híbridos" (GALLO, 2000, p. 6).

A interdisciplinaridade tem como estratégia a união de diferentes disciplinas em busca da compreensão e da resolução de um problema. Nesse âmbito as diversas disciplinas não precisam se afastar de seus conceitos e métodos para contribuir com um projeto ou com a solução de algum problema como já foi mencionado. Num processo interdisciplinar (Philippi, Jr, A., 2000) é importante que haja a união, a participação, o espírito de grupo, o engajamento, a comunicação e a ação. Nas palavras de Gallo (Idem),

$$
\begin{aligned}
& \text { "o sentido geral da interdisciplinaridade é a consciência da } \\
& \text { necessidade de um interrelacionamento explícito entre as } \\
& \text { disciplinas todas. Em outras palavras, a interdisciplinaridade é a } \\
& \text { tentativa de superação de um processo histórico de abstração do } \\
& \text { conhecimento que culmina com a total desarticulação do saber } \\
& \text { que nossos estudantes ( e também nós, professores) têm o } \\
& \text { desprazer de experimentar". }
\end{aligned}
$$

Nesse sentido o papel do educador ambiental no ensino fundamental é muito relevante, já que a Educação Ambiental não é uma matéria somada àquelas existentes e sim um tema transversal que exige a união das disciplinas do currículo além do conhecimento de vários temas da atualidade, o que se constitui num desafio, que obrigatoriamente leva à uma constante pesquisa por parte dos profissionais. Tal desafio 
(Gallo, 2001), faz com que os cientistas comecem a explorar as fronteiras entre as ciências e a partir dessa exploração se constrói a proposta da interdisciplinaridade, numa tentativa de restabelecer as ligações perdidas com as especializações. Assim, podemos depreender que a interdisciplinaridade é um processo de cooperação e intercâmbio entre as diversas áreas do conhecimento e de campos profissionais, que enriquecem a abordagem de um tema, sem privilegiar uma disciplina ou outra, pois envolve um trabalho que exige parcerias constantes. Para Japiassu (1976, p.75),

"Estamos diante de um processo interdisciplinar todas as vezes em que ele conseguir incorporar os resultados de várias especialidades, que tomar de empréstimo a outras disciplinas certos instrumentos e técnicas metodológicas, fazendo uso dos esquemas conceituais e das análises que se encontram nos diversos ramos do saber, a fim de faze-los integrarem e convergirem, depois de terem sido comparados e julgados. Donde podemos dizer que o papel específico da atividade interdisciplinar consiste, primordialmente, em lançar uma ponte para religar as fronteiras que haviam sido estabelecidas anteriormente entre as disciplinas com o objetivo preciso de assegurar a cada uma seu caráter propriamente positivo, segundo modos particulares e com resultados específicos".

A Educação Ambiental requer conhecimento de caráter social como: valores culturais, morais, justiça, saúde, a noção de cidadania, entre outros aspectos que conformam a totalidade social. Deve ser tratada a partir de uma matriz que conceba a educação como elemento de transformação social apoiada no diálogo e no exercício da cidadania. Mais, do que isto, "no fortalecimento dos sujeitos, na superação das formas de dominação capitalistas e na compreensão do mundo em sua complexidade e da vida em sua totalidade" (LOUREIRO, 2009, p. 24).

A educação para a cidadania requer uma abordagem que seja cada vez menos fragmentada, que envolva metodologias interdisciplinares e inclua as questões sociais e que estas sejam submetidas à aprendizagem e à reflexão dos alunos, a partir de um tratamento didático que perceba a sua complexidade e dinâmica, atribuindo-lhes a mesma importância das áreas convencionais. Desta forma o currículo ganha em flexibilidade e abertura, já que os temas podem ser contextualizados e priorizados 
conforme as diversas realidades locais e regionais, possibilitando ainda a inclusão de novos temas (GALLO, 2001).

Os Parâmetros Curriculares Nacionais (PCN) criados pelo Ministério da Educação em 1998, indicam que a aprendizagem de valores e atitudes deve ser mais explorada do ponto de vista pedagógico e o conhecimento dos problemas ambientais e de suas conseqüências desastrosas para a vida humana é importante para promover uma atitude de cuidado e atenção com essas questões, incentivar ações preservacionistas (BRASIL, 1998).

A Educação Ambiental contribui fortemente para o processo de conscientização levando à mudanças de hábitos e atitudes do homem e sua relação com o ambiente. Destacamos ainda que a Educação Ambiental trás a questão de que há uma necessidade de se buscar a democratização da cultura, do acesso e permanência na escola bem como da melhora do nível cultural da população para compreender o que é ciência, os avanços científicos e tecnológicos e as possibilidades de solução para diversos problemas de nossa época LOUREIRO (2004, p.89). compartilha da mesma idéia ao expressar que a Educação Ambiental deve possuir um conteúdo emancipatório, onde

"as alterações da atividade humana, vinculadas ao fazer educativo possam conferir mudanças individuais e coletivas, locais e globais, estruturais e conjunturais, econômicas e culturais".

A idéia expressa por Freire (2000) é a de que temos que assumir o dever de lutar pelos princípios éticos fundamentais como o respeito à vida humana, aos animais, aos rios e às florestas. Portanto, deve estar presente em qualquer prática educativa de caráter crítico ou libertador.

Uma das coisas que tem sido fonte de preocupação é o consumo de alimentos sem agrotóxicos produtos químicos usados na lavoura, na pecuária com o objetivo de combater insetos fungos, ácaros que causam algum tipo de dano à lavoura. Ou para a limpeza e desinfecção de instalações de animais domésticos; baias e estábulos. O manuseio inadequado de agrotóxicos é um dos principais responsáveis por acidentes de trabalho no campo (SILVA, Jandira Maciel da et al, 2005; PERES, Frederico \& MOREIRA; Josino Costa (Orgs.), 2003) .

A ação destas substâncias no organismo humano, sobretudo através da ingestão de alimentos contaminados é lenta e leva bastante tempo para se manifestar. $\mathrm{O}$ seu acúmulo no organismo pode provocar doenças como câncer, fetos com má- 
formação, abortos, perturbações mentais que levem ao suicídio problemas de pele entre outras doenças.

No que se refere ao ambiente, o mau uso e a ausência de cuidados com esses produtos provocam um acúmulo em diversos locais, fazendo com que se espalhem em outros ambientes, tornando impuros recursos hídricos e outros biomas. Na década de 60 Rachel Carson demonstrou como os agrotóxicos permanecem no solo, penetravam na cadeia alimentar, acumulando-se nos tecidos gordurosos dos animais inclusive do homem, além de ter sido identificado no leite materno, levando a risco de câncer e graves alterações genéticas.

Ruscheinsky (2002), aponta para a necessidade de conferir a agricultura um caráter mais auto-sustentável e menos agressivo à natureza como atualmente é a agricultura convencional. Nesse sentido a chamada agricultura ecológica surge como uma alternativa que confere inúmeros benefícios aos produtores, aos consumidores e para o meio ambiente como um todo. Este tipo de agricultura exclui do seu sistema de produção o uso de fertilizantes sintéticos de alta solubilidade e agrotóxicos, além de reguladores de crescimento e aditivos sintéticos para a alimentação animal. A recomendação é que seja utilizado o estercos animais, rotação de culturas, adubação verde, compostagem e controle biológico de pragas e doenças. Este sistema procura manter a estrutura e produtividade do solo, trabalhando em harmonia com a natureza.

A importância da Educação Ambiental proporciona aos alunos conhecimentos sobre um tipo de agricultura mais natural, o perigo da utilização de agrotóxicos e o mal que estas substâncias causam à saúde humana, aos animais e aos ecossistemas. Também é uma maneira dos estudantes descobrirem a importância dos legumes e verduras para a nossa saúde. Além disso, a possibilidade de sair da sala para assistir aula em um espaço aberto, e estar em contato direto com a terra, com a água, poder preparar o solo, conhecer e associar os ciclos alimentares de semeadura, plantio, cultivo, ter cuidado com as plantas e colhê-las torna-se uma diversão. Além de representar um momento em que os alunos aprendem a respeitar a terra. Sem dúvida a combinação destes conhecimentos leva os alunos à compreensão de que o solo fértil contém bilhões de organismos vivos e que estes são microorganismos que realizam transformações químicas fundamentais para a manutenção da vida na Terra. Conforme prepondera Capra (2005) em razão da natureza do solo vivo temos que preservar a integridade dos grandes ciclos ecológicos em nossas práticas agrícolas e de jardinagens. Essa perspectiva apóia-se num profundo respeito pela vida e faz parte de muitos métodos 
tradicionais de cultivo da terra que estão sendo atualmente resgatados pela agricultura ecológica, pela agricultura orgânica, pela agricultura biodinâmica, entre outros.

Nesse sentido afirmamos que a horta escolar é o espaço propício para que as crianças aprendam os benefícios de formas de cultivo mais saudáveis. Além disso, aprendem a se alimentar melhor, pois como se sabe, as crianças geralmente não gostam de comer verduras e legumes e o fato de cultivar o alimento que levarão para casa os estimula a comê-los, especialmente quando conhecem a origem dos vegetais e sabem que são cultivados sem a adição de insumos químicos. Aumentar o consumo de frutas, legumes e verduras tem sido um dos principais recomendações e um desafio para a saúde pública, Existe várias razões diferenciadas entre as populações, para não consumirem frutas, legumes e verduras, dentre as quais, preço, conveniência, sabor entre outras. A evidência científica tem demonstrado e recomendado o consumo de frutas, legumes e verduras como e

\footnotetext{
"cada vez mais, instituições nacionais de saúde e agricultura, representantes da indústria e de organizações internacionais, incluindo a FAO, têm trabalhado para acessar esses obstáculos e discutir formas de promover o consumo de frutas, legumes e verduras ao redor do mundo" (FAO, 2006; GOMES, 2007)
}

O espaço da horta escolar é caracterizado por Capra (idem) como um local capaz de religar as crianças aos fundamentos básicos da comida e ao mesmo tempo integra e enriquece todas as atividades escolares. As atividades na horta despertam para não depredar, mas para conservar o ambiente e a trilhar os caminhos para alcançar o desenvolvimento sustentável.

A partir das atividades desenvolvidas na horta, os alunos ficam sensibilizados com a preservação do ambiente escolar, identificando áreas degradadas nos jardins, bueiros entupidos por falta de limpeza periódica e preventiva, que impossibilita o escoamento de água da chuva ocasionando muitas vezes o empoçamento em vários pontos do colégio. Tal situação pode contribuir para que procurem a direção da Instituição de ensino, apresentem o que foi identificado por eles e acabem assim levando a limpeza dos bueiros. Além disso, os alunos passam a ter atenção e cuidado com os animais silvestres, que eventualmente possam aparecer no colégio em busca de alimentos nas lixeiras da cantina e que usualmente são maltratados por alguns estudantes. 
As atividades desenvolvidas na horta também promovem a oportunidade de muitas crianças estabelecerem contato com a natureza, pois muitas delas perderam esta possibilidade, pois muitas famílias residem em edifícios ou em casas cujos quintais são muito pequenos e cimentados. Ao manipularem a terra muitos estudantes adquiriram também maior habilidade manual, melhoram a coordenação motora, a habilidade manual além de adquirir mais força nas mãos.

A questão ambiental possui um caráter amplo e complexo, pois envolve diversos campos do saber. Tal aspecto exige uma abordagem cada vez menos fragmentada, carecendo da utilização de métodos interdisciplinares, com uma visão sistêmica, um pensamento holístico (Capra, 1982; Leff, 2001) que possibilite restabelecer uma determinada realidade na sua totalidade.

Nesse sentido, a Educação Ambiental requer uma abordagem interdisciplinar, já que lida com a realidade, adota uma abordagem que considera todos os aspectos que compõem a questão ambiental e sociocultural e procura conforme Oliveira (2003) estabelecer um diálogo entre as diversas culturas presentes nos mais diversos espaços/tempos sociais. Onde a vida cotidiana não é apenas lócus de repetição, é também, e, sobretudo, espaço/tempo de produção de conhecimentos válidos e necessários (ALVES, 2004).

Um trabalho de ensino-aprendizagem precisa ser conduzido a partir de uma visão integradora, voltada para as realidades ecológica, econômica e sociocultural de cada indivíduo, de cada sociedade, de cada região. Assim sendo, um trabalho de ensinoaprendizagem como este nos remete àquilo que prepondera Oliveira (2004, p. 9) ao abordar questões relacionadas às alternativas curriculares, sobretudo como possibilidade de contribuição para a emancipação social, de que o currículo não é apenas

"uma lista de conteúdos a serem ministrados a um determinado grupo de sujeitos, mas como criação cotidiana daqueles que fazem as escolas e como prática que envolve todos os saberes e processos interativos do trabalho pedagógico realizado por alunos e professores".

Além disso, Oliveira (Idem) expressa a idéia de que, “a vida cotidiana tem seus próprios currículos, expressos nos processos sociais de aprendizagem que permeiam todo o nosso estar no mundo e que nos constituem. Nesse sentido, alternativas curriculares, desenvolvidas dentro e/ou fora da escola, que podem 
ser entendidas como contribuição para a emancipação social na medida em que representam experiências voltadas para o conhecimento-emancipação (...). Como redes de práticas habitadas tanto por presenças quanto por ausências, os fazeres pedagógicos aqui apresentados ganham sentido emancipatório, voltando-se para a superação do colonialismo e buscam caminhar em direção à solidariedade".

Oliveira (idem) também aborda o aspecto da criatividade, para além daquilo que é imposto ou norma curricular, ou seja, as artes do currículo, são as maneiras que se fazem, produzem currículos reais através de procedimentos e mecanismos que procuram o desenvolvimento de uma ação educativa mais eficaz.

Assim, durante as aulas é possível resgatar a história da agricultura e através dela é apresentar como o ser humano desde a pré-história vem buscando através das práticas agrícolas garantir o seu sustento. Foram muitos os caminhos percorridos pela humanidade. Primeiro o homem atravessou o chamado período mítico-religioso, através do qual ele acreditava que as boas colheitas ocorreriam devido à interferência dos deuses e às suas superstições.

Num segundo período histórico o homem passa a observar a natureza com mais atenção e procura imitá-la na busca de obter melhores colheitas.

A partir do momento em que a ciência é criada o homem começa a aprimorar as suas técnicas e a aperfeiçoar e ampliar o modo de produzir.

As modificações sofridas nas técnicas aplicadas à agricultura, como a utilização de insumos químicos no controle de plantas invasoras, fertilizantes, maquinários pesados, desmatamentos para a formação de pastos ou para grandes plantações, novas variedades genéticas, irrigação, entre outros, acentuou a degradação ambiental e aumentou os riscos à saúde humana. A utilização de agrotóxicos e outros produtos perigosos para o meio ambiente, levaram a uma exploração excessiva e ao desgaste dos ecossistemas acarretando graves problemas ao meio ambiente.

O desenvolvimento da ciência trouxe muitos benefícios, mas também produziu muitos malefícios. Ao mesmo tempo em que a indústria prosperou, a população aumentou e se concentrou, a poluição surgiu e atingiu níveis tão alarmantes que se tornou uma preocupação constante em nossas vidas. Tal aspecto levou a sociedade civil a se organizar e a estabelecer formas de defesa do meio ambiente e uma destas foi o desenvolvimento sustentável - criado na década de 80 , cuja definição mais aceita é "o 
desenvolvimento capaz de suprir as necessidades da geração atual, sem comprometer a capacidade de atender as necessidades das futuras gerações" (CMMAD, 1988). Sua proposta principal é apresentar maneiras de harmonizar o desenvolvimento econômico e a conservação ambiental. Para atingirmos o desenvolvimento sustentável é preciso planejamento e sobretudo reconhecer que os recursos naturais correm risco já que muitos não são renováveis.

Destaca-se que outra atividade muito interessante a ser desenvolvida com os alunos a partir da horta escolar, é a venda de mudas de plantas ornamentais. A partir da produção de espécies destinadas à reposição ou organização dos jardins e jardineiras do colégio, é possível realizar uma feirinha de mudas de plantas ornamentais. As espécies são escolhidas pelos alunos em função da procura e para isto eles terão que fazer uma pesquisa com a comunidade escolar. Após a identificação daquelas espécies mais procuradas, o professor programará com os alunos a distribuição/organização da venda. Um exemplo: No primeiro dia são colocadas para a venda cinco exemplares de cada espécie, totalizando trinta mudas. Se algumas são mais procuradas, os alunos anotam os nomes e na feirinha da semana seguinte organizam as mudas conforme a demanda. Eles também decidirão em que tipo de recipientes as mudas serão plantadas: em copos plásticos descartáveis, garrafas pet, tetra pak, reaproveitados diariamente recolhidos nas lixeiras da cantina do colégio. Esta escolha é ótima alternativa quando não se dispõe de saquinhos para mudas. Outra ótima opção é adotar a perspectiva de reaproveitamento de um tipo de resíduo sólido, pois nas aulas sobre preservação ambiental deve ser apresentado e debatido o problema do lixo. Então ao se depararem com este tipo de problema os alunos podem ser instigados ou terem a idéia de recolher o material e prepara-lo para plantar as mudas.

Após esta etapa sugere-se que os alunos definam os preços, em função da espécie e do tamanho da muda, por exemplo. Durante a feirinha anota-se o nome, o número de plantas vendidas e o preço de cada uma; um dos alunos era escolhido para ser o tesoureiro. No final das feirinhas os próprios alunos fazem a contabilidade e o valor arrecadado após apresentado aos professores pode ser entregue na tesouraria do colégio e destinado às despesas com a própria horta. Esta atividade possibilita a melhor compreensão de alguns conceitos e cálculos matemáticos.

Muitas atividades construtivas podem levar a sensibilização e ao envolvimento dos alunos. Por exemplo, colocar em debate um tema ambiental relevante para a comunidade escolar ou para o seu bairro, ou a sua cidade, contribuindo assim, para 
aumentar a consciência ambiental das pessoas. Dentre estes temas podemos destacar a questão da águas: sua qualidade e a preservação dos recursos hídricos. Outro assunto instigante é o verde de nossas matas, da nossa paisagem e daquilo que podemos definir como natureza urbana, contida nas praças, parques e jardins. Ou ainda uma interessante proposta seria a associação entre História e Natureza no Brasil, apresentar e debater as diversas concepções de natureza que o Brasil tem produzido e vivido, focando a ligação entre natureza e cultura a partir da idéia de que as nossas práticas ambientais estão relacionadas com matrizes culturais antigas, adquiridas dos europeus, indígenas e negros originários da África.

O processo pedagógico pode se desenrolar da seguinte forma: os temas são escolhidos pelos alunos a partir de uma lista sugerida pelos professores. Após a escolha, é realizado o debate sobre o junto com os professores através de palestras e dinâmicas de sensibilização. Findo estes debates, pode ser montada uma oficina onde se trabalha arte e ecologia por exemplo. Nestas oficinas a integração de professores de educação artística e de professores que trabalham temas ambientais ensina as crianças a confeccionarem produtos (bijouterias, enfeites, acessórios) a partir de material reaproveitado: anéis de latinhas de alumínio, garrafas pet, tampinhas, caixas tetra pak, sacolas plásticas, pedaços de fita, de tecido, de emborrachados, folhas secas, sementes, entre outros materiais. Os alunos podem ainda ser estimulados a criar uma música que apresente o tema por eles escolhidos.

Durante datas comemorativas as crianças terão a oportunidade de mostrar seus trabalhos e de falar sobre o processo de confecção. Outra atividade interessante é a apresentação de peças de teatro ou filmes sobre temas socioambientais e a partir destes ser estimulado um debate sobre o assunto com a comunidade escolar.

O conjunto destas atividades, tanto na sala de aula convencional, como na horta ou em outras atividades extra-classe leva os alunos ao exercício da cidadania. Contribui para adquirirem novos valores, novas percepções e novas formas de pensar, através do trabalho em equipe, da solidariedade, da cooperação, do desenvolvimento da criatividade, da percepção da importância do cuidado, do senso de responsabilidade, de autonomia e, sobretudo da sensibilidade e de assumir novas atitudes em relação à busca de soluções para os problemas ambientais.

Bons projetos com esta temática tem sido desenvolvido em vários lugares, dentre os quais destacamos o Projeto Educando com a horta escolar promovido pelo Fundo Nacional de Desenvolvimento da Educação (FNDE/MEC), cujo objetivo é 
“formar formadores municipais nas áreas de Educação, Meio Ambiente/Horta e Nutrição, para organização, implantação e desenvolvimento do Projeto no município, com vistas à melhoria da qualidade de alimentação, do meio ambiente e do corrículo escolar" (FNDE/MEC, 2005). Destaca-se também, as atividades realizadas na Escola Estadual Prof ${ }^{\circ}$ Salvador Gogliano Júnior, no município de Vista Alegre do Alto, São Paulo, com 48 crianças da $5^{\text {a }}$ sério do Ensino Fundamental, um trabalho interdisciplinar e com a Prefeitura Municipal que concedeu um local próximo à Escola para a construção de uma horta orgânica, bem como a doação de materiais apropriados para os tratos culturais e a promoção do trabalho para a comunidade (DI GIOVANNI \& ZANETTI, 2006). Outro interessante trabalho foi desenvolvido em uma escola pública no município de Parobé no Rio Grande do Sul (Fetter, et al, 2006), onde os alunos desenvolveram a produção de hortaliças para a merenda escolar. Para trabalhar questões sobre o uso e a proteção do solo foram aproveitados resíduos orgânicos para a construção de uma composteira em um tonel metálico onde se estabeleceu uma criação de minhocas. Além dos resíduos orgânicos foi estimulado o aproveitamento de resíduos sólidos como potes e caixas de leite vazias. Este trabalho teve como objetivo principal desenvolver nos alunos a compreensão da agricultura familiar e o desenvolvimento de técnicas de cultivo relacionadas ao desenvolvimento sustentável. Além disso, promover a capacidade para o trabalho em equipe, a cooperação, o respeito e o senso de responsabilidade, a alimentação alternativa livre de agrotóxicos.

A questão pedagógica, não é apenas a questão da aprendizagem, mas também a dos valores fundadores da ação: humanismo, respeito aos outros, democracia, trocas e solidariedade. Portanto, é fundamental que esses valores não sejam negados pela prática institucional e/ou por uma pedagogia que não esteja em coerência com eles (NOËLEVEN, 2004).

A construção de uma outra sociedade mais justa, solidária, pacífica e sustentável se apresenta cada dia mais utópica e distante e ao mesmo tempo urgente, necessária e pertinente. Assim se multiplicam em todo o mundo os espaços de encontro dos anônimos e anônimas que investem seu tempo e energia na construção dessa sociedade que não sabermos muito bem como será, e de que temos apenas alguns indícios de como queremos que seja (REIGOTA, 2004, p. 209). 


\section{Considerações finais}

As atividades na horta escolar e sobretudo a partir da Educação Ambiental, representam aquilo que Oliveira (2004) considera como um modo diferente de reinventar o fazer pedagógico, através da criação cotidiana de uma alternativa curricular emancipatória, cujo resultado vai ao encontro da idéia de uma educação para a (e na) cidadania onde podemos compreender melhor que cada um de nós se forma enquanto uma rede de sujeitos, e sendo assim, a fragmentação tanto dos saberes quanto das dimensões da vida, tanto não faz sentido como prejudica a formação (PACHECO, 2004; OLIVEIRA, 2004).

No que se refere a educação para a cidadania e a responsabilidade com o meio ambiente, damos voz a Loureiro (2009, p,58):

"Cabe a Educação Ambiental gerar um sentido de responsabilidade social e planetária que considere o lugar ocupado pelos diferentes grupos sociais, a desigualdade no acesso e uso de bens materiais e nos efeitos desse processo, as diferentes culturas e modos de entender a ameaça à vida no planeta, problematizando as ideologias e interesses existentes por trás dos múltiplos modelos de sociedades sustentáveis que buscam se afirmar no debate ambientalista. Fazemos a nossa história em comunhão com o planeta, mas fazemos em certas condições e no âmbito de uma determinada organização social, e somente podemos nos modificar e a tais condições reconhecendo e agindo nas diferentes esferas da vida, e entendendo a educação não como único meio para a transformação mas como um dos meios sem o qual não há mudança."

As atividades desenvolvidas nas aulas contribuem para conscientizar alunos de diferentes séries acerca da temática ambiental, levando-os a um interesse maior no conhecimento e nas relações estabelecidas com o meio ambiente através da experiência com a horta. Também permite que compreendam a necessidade da conservação dos ecossistemas, do reaproveitamento de resíduos sólidos e da importância das hortaliças para a saúde humana. CRIBB, S. L. S. P.; CRIBB, André Yves 2009; CRIBB, S. L. S. $\mathrm{P}, 2007)$. Ao cuidar da horta os alunos adquirem novos valores, novas formas de pensar e mudam suas atitudes em relação aos cuidados com a vida. Já que, através do trabalho 
em equipe, da solidariedade, das práticas do cuidar, da cooperação desenvolvem o senso respeito e de responsabilidade, de autonomia e da sensibilidade em compreender que os ciclos ecológicos estão presentes na vida de todos os seres vivos e estes precisam de respeito, atenção e cuidado. As atividades desenvolvidas em aulas com este perfil demonstram que a educação ambiental além de estar presente nos projetos pedagógicos pode e deve ser abordada em todos os segmentos escolares e por todas as disciplinas.

O cuidado está na essência humana. É o cuidado que permite a priorização do social sobre o individual e ainda contribui para orientar na busca da melhoria da qualidade de vida tanto dos humanos como de outras formas de vida.

"O cuidado imprimiu sua marca registrada em cada porção, em cada dimensão e em cada dobra escondida do ser humano. Sem o cuidado o humano se faria inumano. Tudo o que vive precisa ser alimentado. Assim o cuidado, a essência da vida humana, precisa também ser continuamente alimentado. As ressonâncias do cuidado são sua manifestação concreta nas várias vertebrações da existência e, ao mesmo tempo, seu alimento indispensável. O cuidado vive do amor primal, da ternura, da carícia, da compaixão, da convivialidade, da medida justa em todas as coisas. Sem cuidado, o ser humano, como um tamagochi, definha e morre. Hoje, na crise do projeto humano, sentimos a falta clamorosa de cuidado em toda parte. Suas ressonâncias negativas se mostram pela má qualidade de vida, pela penalização da maioria empobrecida da humanidade, pela degradação ecológica e pela exaltação exacerbada da violência" (BOFF, 2008, p. 190191).

A construção de valores mais humanizados deve permear todo o processo educativo para que se estabeleçam desde cedo relações saudáveis com o meio ambiente e entre as pessoas, para que se formem cidadãos capazes de assumir novas atitudes em relação à busca de soluções para os problemas sociais e ambientais.

\section{Referências bibliográficas}

ALVES, N. (org.). Criar currículo na cotidiano. São Paulo: Cortez Editora, 2004. Série Cultura, Memória e Currículo; vol. 1. 
BOFF, Leonardo. Saber cuidar: ética do humano - compaixão pela terra. Petrópolis: Vozes, 2008.

BRASIL. Ministério da Educação. Parâmetros curriculares nacionais: terceiro e quarto ciclos - apresentação dos temas transversais. Brasília: MEC/SEF, 1998.

CMMAD (Comissão Mundial sobre Meio Ambiente e Desenvolvimento). Nosso Futuro Comum. Rio de Janeiro: Editora da Fundação Getúlio Vargas, 1988.

CAPRA, F. O ponto de mutação. São Paulo: Editora Cultrix, 1982.

CAPRA, F. et al. Alfabetização ecológica: a educação das crianças para um mundo sustentável. São Paulo: Editora Pensamento/Cultrix, 2005.

CARSON, Rachel. Silent Spring. Snd

CARVALHO, Isabel Cristina de Moura. Educação Ambiental Crítica: nomes e endereçamentos da educação In: LAYRARGUES, P.P. (coord.). Identidades da educação ambiental brasileira. Ministério do Meio Ambiente. Diretoria de Educação Ambiental. Brasília, Ministério do Meio Ambiente, 2004.

CRIBB, S. L. S. P. A horta escolar como elemento dinamizador da educação ambiental e de hábitos alimentares saudáveis. In: Anais do Encontro Nacional de Pesquisa em Educação em Ciências, 2007, Florianópolis. VI Encontro Nacional de Pesquisa em Educação em Ciências. Florianópolis, 2007.

CRIBB, S. L. S. P. ; CRIBB, André Yves . Agricultura urbana: alternativa para aliviar a fome e para a educação ambiental. In: XLVII Congresso da Sociedade Brasileira de Economia, Administração e Sociologia Rural, 2009, Porto Alegre. Anais - XLVII Congresso da Sociedade Brasileira de Economia, Administração e Sociologia Rural, 2009. Disponível em: http://www.sober.org.br/palestra/5/512.pdf. Acesso em: 23 abril 2010.

DI GIOVANNI, Patricia Carla; ZANETTI Camila Brunhari. Educação Ambiental e Construção de Horta Orgânica na Escola: Um Alerta sobre o Cultivo e o Consumo de Produtos com Agrotóxicos. Revista Hispeci \& Lema. São Paulo, v. 9, 2006.

Disponível em: http://www.fafibe.br/down/revista/revista9.pdf Acesso em: 23 abril 2010.

FOOD AND AGRICULTURAL ORGANIZATION OF THE UNITED NATIONS (FAO). Increasing fruit and vegetable consumption becomes a global priority. Disponível em: http://www.fao.org/english/newsroom/focus/2003/fruitveg1.htm. Acesso: 24 abril 2007.

FETTER, S. I.; MÜLLER, J.; SILVA, M. C. Horta escolar: teoria e prática para uma vida saudável: educação ambiental na Escola Estadual João Mosmann/Parobé/RS. Revista Brasileira de Agroecologia. Vol. 1 n ${ }^{\circ} .1$ Nov. 2006.

FREIRE, P. Pedagogia da indignação: cartas pedagógicas e outros escritos. São Paulo. Editora Unesp, 2000. 
FUNDO NACIONAL DE DESESENVOLVIMENTO DA EDUCAÇÃO (FNDE/MEC). Educando com a horta escolar, 2005. Disponível em: http://www.educandocomahorta.org.br Acesso em: 22 abril 2010.

GALLO, S. Transversalidade e educação: pensando uma educação não-disciplinar. In: ALVES, N.; GARCIA, R. L. (orgs.) O Sentido da Escola. Rio de Janeiro: DP\&A, 2000. Disponível em: http://www.cursoideb.utopia.com.br/tikiindex.php?page $=$ Transversalidade+e+educa\%C3\%A7\%C3\%A3o+de+Silvio+Gallo Acesso em: 29 ser 2009.

GALLO, S. Transversalidade e meio ambiente. In: Ciclo de palestras sobre o meio ambiente. Brasília: MEC/SEF, 2001.

GOMES, Fabio da Silva. Frutas, legumes e verduras: recomendações técnicas versus constructos sociais. Rev. Nutr., Campinas, 20(6):669-680, nov./dez., 2007 Disponível em: http://www.scielo.br/pdf/rn/v20n6/a09v20n6.pdf. Acesso em 24 abril 2010.

GUIMARÃES, M. A Educação Ambiental crítica. In: LAYRARGUES, P.P. Identidades da educação ambiental brasileira. Ministério do Meio Ambiente. Diretoria de Educação Ambiental. Brasília, Ministério do Meio Ambiente, 2004.

JAPIASSU, H. Interdisciplinaridade e patologia do saber. Rio de Janeiro: Imago, 1976.

LEFF, E. Epistemologia ambiental. São Paulo: Editora Cortez, 2001.

LOUREIRO, C.F.B. Trajetória e fundamentos da Educação Ambiental. São Paulo: Editora Cortez, 2009.

NOËL-EVEN, J. O liceu experimental de Saint-Nazaire: uma utopia? In: OLIVEIRA, I.

B. (Org.). Alternativas emancipatórias em currículo. São Paulo: Cortez Editora, 2004. Série Cultura, Memória e Currículo; vol. 4.

OLIVEIRA, I. B. (Org.). Alternativas emancipatórias em currículo. São Paulo: Cortez Editora, 2004. Série Cultura, Memória e Currículo; vol. 4.

PACHECO, J. Fazer a Ponte. In: OLIVEIRA, I. B. (Org.). Alternativas emancipatórias em currículo. São Paulo: Cortez Editora, 2004. Série Cultura, Memória e Currículo; vol. 4.

PERES, Frederico e MOREIRA, Josino Costa (Orgs.). É Veneno u Remédio? agrotóxicos, saúde e ambiente. Rio de Janeiro: Editora Fiocruz, 2003.

PHILIPPI JR, A. (Org). Interdisciplinaridade em Ciências Ambientais. São Paulo: Cegos, 2000. 
REIGOTA, M. Fórum Social Mundial: um processo pedagógico de desconstrução de mitos e construção utópica. In: OLIVEIRA, I. B. (Org.). Alternativas emancipatórias em currículo. São Paulo: Cortez Editora, 2004. Série Cultura, Memória e Currículo; vol. 4.

RUSCHEINSKY, A. Educação ambiental, abordagens múltiplas. Porto Alegre: Artmed, 2002.

SILVA, Jandira Maciel da et al . Agrotóxico e trabalho: uma combinação perigosa para a saúde do trabalhador rural. Ciênc. saúde coletiva, Rio de Janeiro, v. 10, n. 4, dez. 2005 . Disponível em <http://www.scielo.br/scielo.php?script=sci_arttext\&pid=S141381232005000400013\&lng=pt\&nrm=iso>. acessos em 24 abr. 2010 . doi: $10.1590 /$ S1413-81232005000400013.

SORRENTINO, M. et al. Educação ambiental como política pública. Educação e Pesquisa. São Paulo, v. 31, n. 2, 2005. Disponível em:

$<$ http://www.scielo.br/scielo.php?script=sci_arttext\&pid=S1517-

97022005000200010\&lng=pt\&nrm=iso>. Acesso em: 05 Jun. 2007 